\title{
MICROGYRIA AND CYTOMEGALIC INCLUSION DISEASE IN INFANCY
}

\author{
BY \\ L. CROME AND N. E. FRANCE \\ From the Fountain Hospital and the Mothers' Hospital (Salvation Army), London
}

(RECEIVED FOR PUBLICATION APRIL 13, 1959)

Many different malformations of the central nervous system can now be produced in the offspring of animals exposed during pregnancy to $x$ rays, drugs, and dietetic deficiency or excess of vitamins, but proof of environmental causation of analogous human conditions is understandably scarce. Occasional neural, somatic, or gonadal maldevelopment has been reported after the administration to pregnant women of aminopterin (Thiersch, 1956), thiouracil (Morris, 1953), methyltestosterone (Nellhaus, 1958), and progesterone (Reilly, Hinman, Pickering, and Crane, 1958; Wilkins and Jones, 1958). Nevertheless, maternal rubella and ionizing radiation remain the only widely known extrinsic causes of human embryopathy. Hence the importance of the suggestion that another, probably infective, condition, cytomegalic inclusion disease, may be also responsible for neural malformation (Diezel, 1954).

It has been known for some time that the brain is one of the organs which may display the characteristic inclusions of cytomegalic inclusion disease. Haymaker, Girdany, Stephens, Lillie, and Fetterman (1954) collected seven such cases in the literature and added one of their own. In addition to the inclusions, some of these brains showed hydrocephalus, periventricular calcification, focal softening, haemorrhages, astrocytic proliferation, perivascular inflammatory infiltration, and ependymal granulations. These are, of course, evidence of neural disease, but not necessarily of malformation. Diezel was the first to report the association of cytomegalic inclusion disease with microgyria, or micropolygyria. Microgyria is a true cerebral malformation characterized by an excess of small abnormally formed gyri (Crome, 1952). Histological and embryological considerations suggest that the cause of this condition operates before the sixth month of foetal development.

The patient described by Diezel was an infant weighing $2,500 \mathrm{~g}$. at birth who developed neonatal jaundice, ascites with hepatomegaly, and splenomegaly, and died at 24 days. Inclusion bodies were found in the kidneys, liver, and brain. The brain weighed $130 \mathrm{~g}$. and showed microgyria of the neocortical areas. Necrosis was present in the medial basal regions of both temporal lobes and in the cerebellum. The optic nerves were atrophic, there was marked hydrocephalus, and the corpus callosum was thin. On microscopy, the necrotic areas showed infiltration by lymphocytic and plasma cells with many compound granular corpuscles, macrophages, and calcified particles. The olfactory nerves were the seat of marked inflammatory change. Typical inclusions of cytomegalic inclusion disease were seen in the leptomeninges, ependymal, and glial cells, as well as in some of the undifferentiated matrix cells arranged in numerous dense periventricular foci. The only mature neurons to show inclusions were a few Purkinje cells, found after prolonged search. Architectonically, the palaeocortex and archicortex were normal and the relatively older occipital cortex was better developed than the rest of the neocortex. It appeared therefore to the author that the virus of cytomegalic inclusion disease attacked the foetus at a time when migration of nerve cells from the periventricular matrix to the periphery was complete in the older, and still afoot in the newer, parts of the brain, i.e., the beginning of the fourth month of gestation.

Diezel was able to re-examine histological preparations from the brains of the two cases of cytomegalic inclusion disease previously reported by Hartmann (1948) and by Haymaker and his co-workers. He found microgyria in one of these, whilst the other had an anomaly of gyri, possibly of microgyric nature. Microgyria was possibly present in a case of cytomegalic inclusion disease presented by Mercer, Luse, and Guyton (1953) ; the brain of this child had an irregular, thin-walled cyst, $1.5 \mathrm{~cm}$. in diameter, in the right parietal lobe, the cortical surface around the cyst was slightly 
depressed and firm, while the irregular narrow gyri in this area had a "wrinkled" surface. A further definite example of cytomegalic inclusion disease with microgyria was recently demonstrated in this country by Strich (1958, personal communication), and it is the object of this communication to record another case.

\section{Case Report}

This girl was the issue of the second pregnancy of a 25-year-old unmarried mother. Two years previously, she had had a miscarriage at 3 months, followed a few months later by possible glandular fever with lymphadenopathy and a rash. The PaulBunnell test was not done. Apart from slight vaginal bleeding at the 12th week of gestation, her second pregnancy was normal and the labour began spontaneously at 32 weeks. Labour was complicated by mild ante-partum haemorrhage and resulted in delivery by the vertex of a female infant weighing $2,020 \mathrm{~g}$. The placenta $(760 \mathrm{~g}$.) was large and friable.

At birth, the baby showed numerous skin haemorrhages of face, trunk, and lower limbs. The abdomen was huge and lax with considerable enlargement of the liver and spleen. Respirations were moaning and grunting and there was much rib recession. The submaxillary salivary glands were not enlarged. In spite of oxygen therapy and treatment with penicillin and streptomycin, her condition rapidly deteriorated; moaning respirations continued and occasional convulsive movements preceded death at 31 hours.

\section{Investigations}

Mother.-The blood group was $\mathrm{O}, \mathrm{Rh}$ negative (to anti-D). The serum contained no atypical antibodies, and anti-A and anti-B titres were within normal limits.

Baby.-The blood group was B, Rh positive (to antiD). The direct Coombs test was negative. Serum bilirubin (at birth) was $2.3 \mathrm{mg}$. per $100 \mathrm{ml}$. Capillary blood contained $10.36 \mathrm{~g}$. haemoglobin per $100 \mathrm{ml}$. (Haldane). Colour index was 1.32 ; R.B.C.s $2.64 \mathrm{~m}$. per c.mm.; total nucleated cells, 12,700 per c.mm.; platelets, 142,000 per c.mm.

\section{Pathological Findings}

The body weighed $1,910 \mathrm{~g}$., and was $43.5 \mathrm{~cm}$. (crown-heel) long. The head was microcephalic, the circumference measuring $27 \mathrm{~cm}$. compared with $34.7 \mathrm{~cm}$. which is the mean for this age. The abdominal circumference was $37 \mathrm{~cm}$. There was generalized mild oedema and slight jaundice, with numerous haemorrhages into the skin, conjunctivae, and umbilical cord.

The heart showed marked dilatation of the right side, and patency of the ductus arteriosus. The lungs (R. 13 g., L. 11 g.) were pale purple and poorly aerated. The spleen weighed $14 \mathrm{~g}$. (average normal for age, $6 \mathrm{~g}$.) and showed patchy capsular thickening. The liver weighed $112 \mathrm{~g}$. (average normal for age, $88 \mathrm{~g}$.). It was light green and had a few small subcapsular groups of cysts 1-2 mm. in diameter. The gall-bladder contained colourless mucoid material. The peritoneal cavity contained about $200 \mathrm{ml}$. of clear yellow fluid. The stomach showed a small mucosal erosion. The small intestine contained meconium and was bound together by fine fibrous adhesions. The large intestine was collapsed, containing only pale green mucus. The thymus weighed $5 \mathrm{~g}$. and the left femur was normal. The occipital bone was firmly united with both parietal bones and showed a prominent posterior projection. There were small haemorrhages in the dura.

Histologically, the lungs showed extensive aspiration of amniotic fluid and areas of wellmarked hyaline membrane formation with occasional alveolar haemorrhages. A single large cell was seen in one of the sections which was attached to the alveolar lining and contained a large oval intranuclear inclusion separated by a clear halo from the nuclear membrane showing condensation of chromatin. Its cytoplasm contained many small basophilic inclusions.

The spleen showed diffuse generalized? haemopoiesis. Many haemopoietic foci were also present in the liver, which showed a considerable accumulation of haemosiderin in the parenchymal and Kupffer cells. The subcapsular cysts were lined by fibrillary material and were separated from the capsule by a thin zone of liver cells. A few degenerate inclusion cells were seen in the bile duct of one portal tract.

Both kidneys showed cortical foci of interstitial inflammatory cell infiltration mainly by lymphocytes and plasma cells. Dilated tubules containing many typical inclusion cells were present in some of these inflammatory foci (Fig. 1). Glomeruli were mostly normal, but some were hyalinized and one contained an inclusion cell in a glomerular tuft. There was a moderate amount of haemorrhage into the medulla and excessive haemopoiesis. Many typical inclusion cells without accompanying inflammation were present in the submaxillary salivary gland. The parotid glands were normal.

Central Nervous System.-The unfixed brain weighed $87 \mathrm{~g}$., the range for a baby of $2,000 \mathrm{~g}$. being about 250 to $350 \mathrm{~g}$. from our unpublished observations.

The brain, brain-stem, and cerebellum had been initially cut sagittally through the midline and, 


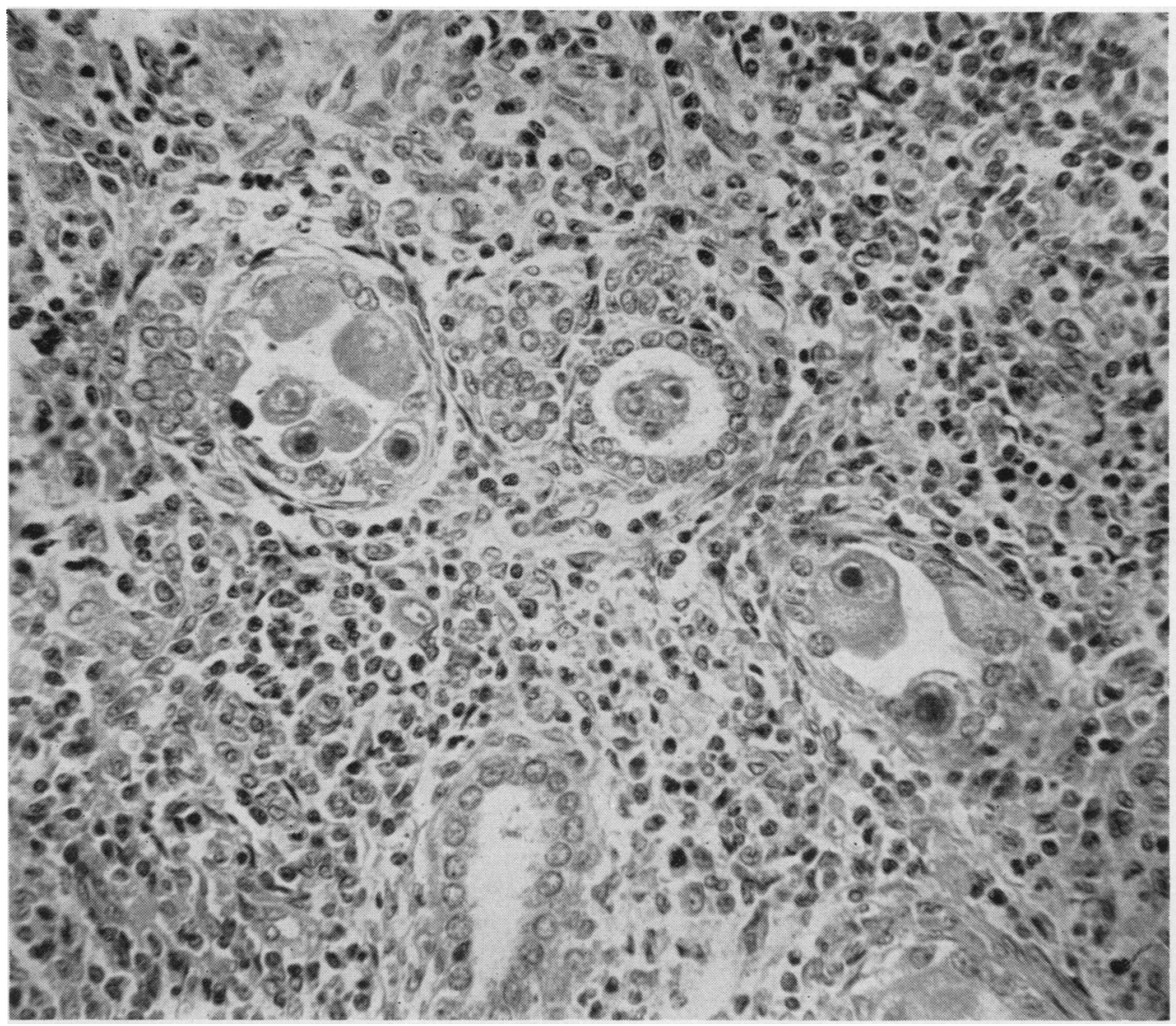

FIG. 1.-Kidney, showing dilated tubules with typical inclusion cells and interstitial inflammatory cell exudate. Haematoxylin and eosin $\times 350$.

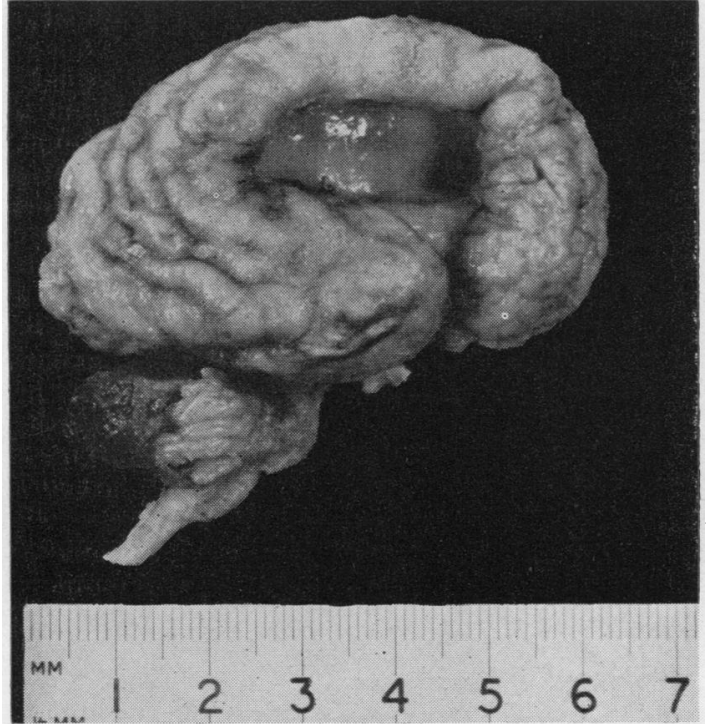

FIG. 2.-External aspect of right cerebral hemisphere.

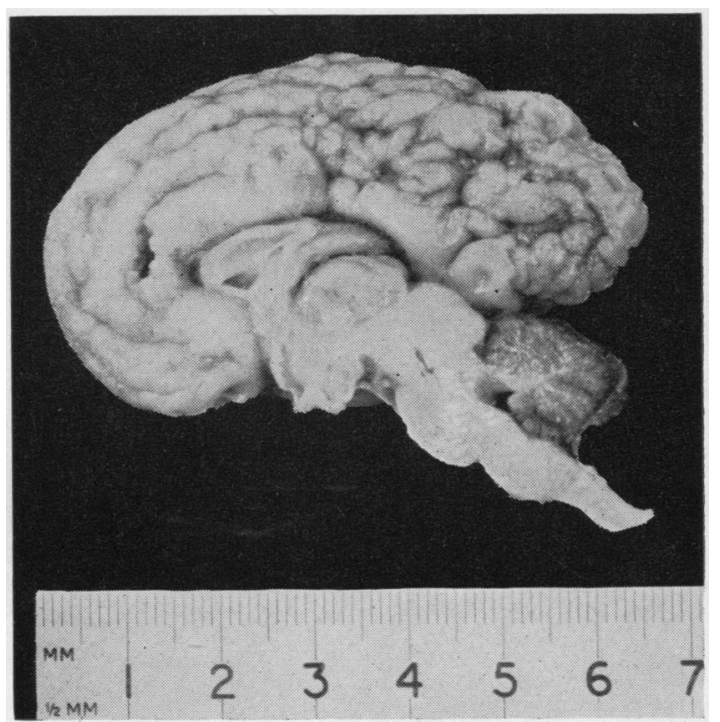

FIG. 3.-Medial aspect of right cerebral hemisphere. 
when re-examined for purposes of the present study five years after death, the material was in two parts. The left side of the brain had been sectioned coronally and partly embedded in paraffin. Additional material was now embedded in celloidin, further sections cut of the paraffin-embedded material, and frozen sections used for fat staining and for silver impregnation methods. The usual general and neurohistological methods were employed. The complete right half of the brain had been stored as a museum specimen in Kaiserling's solution, and, as little was to be gained by sectioning it, only the macroscopic appearances will be presented below.

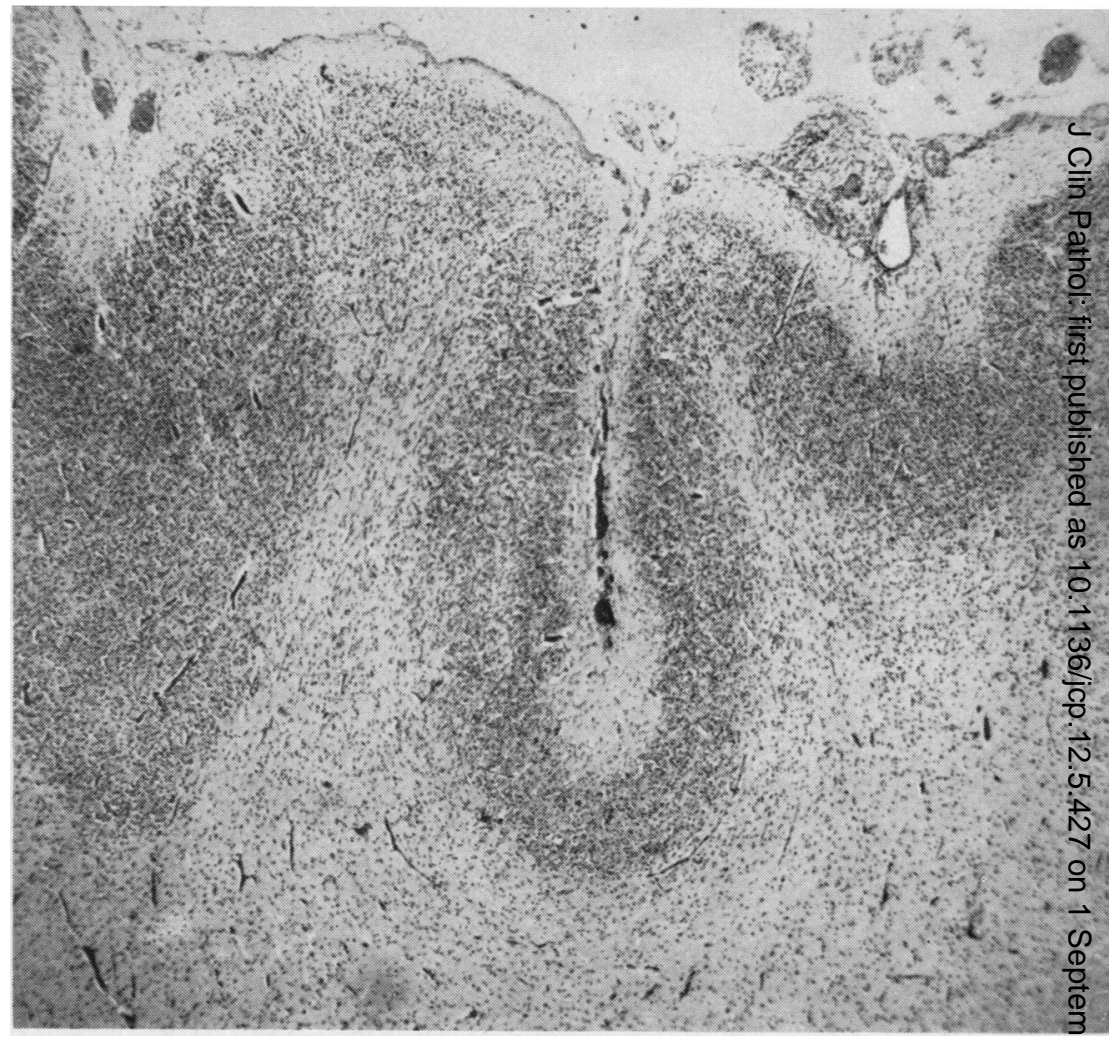

FIG. 4.-Microgyric cortex with area of nerve cell loss at the crown of one of the gyri. Cresyl violet疋 30

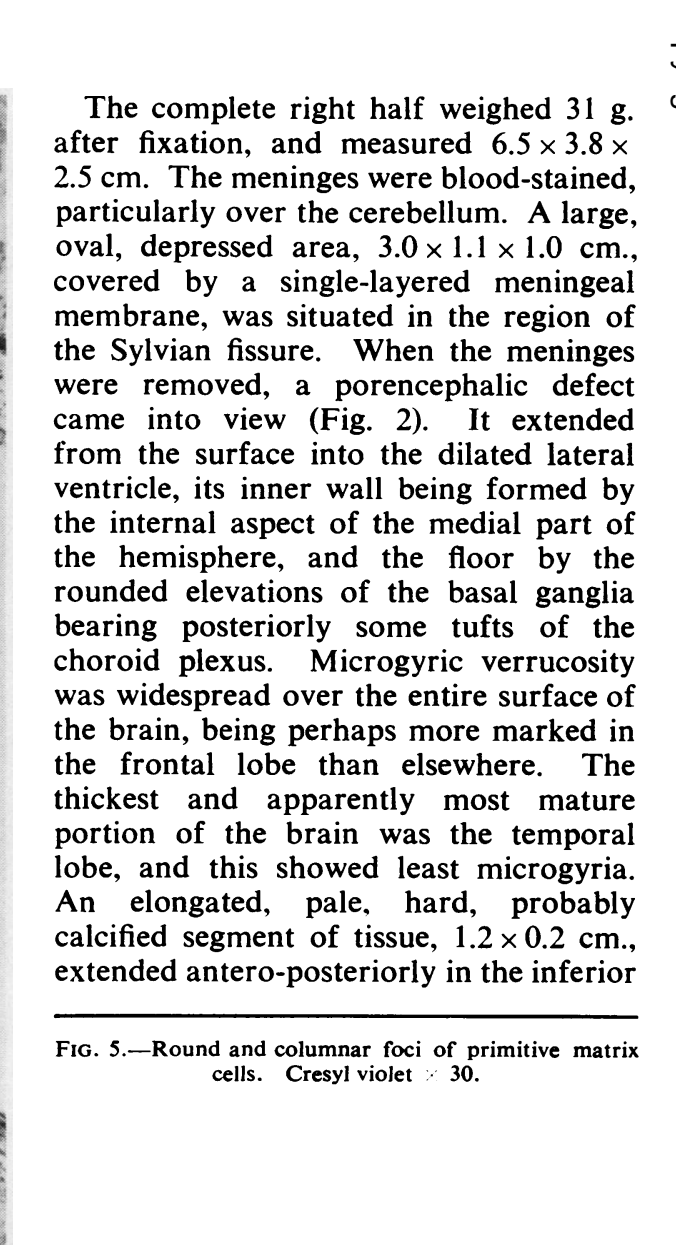
fter complete right half weighed $31 \mathrm{~g}$.

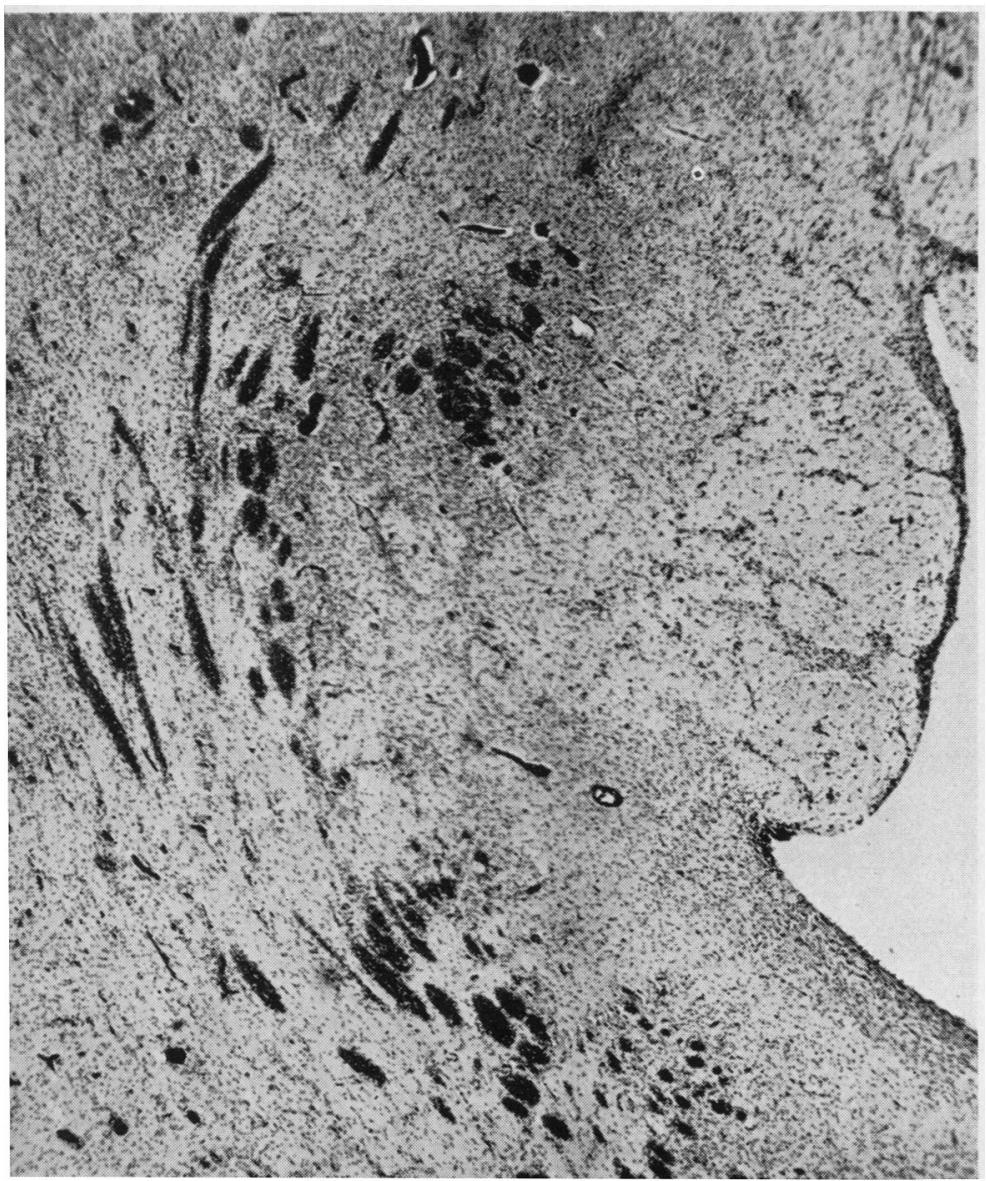




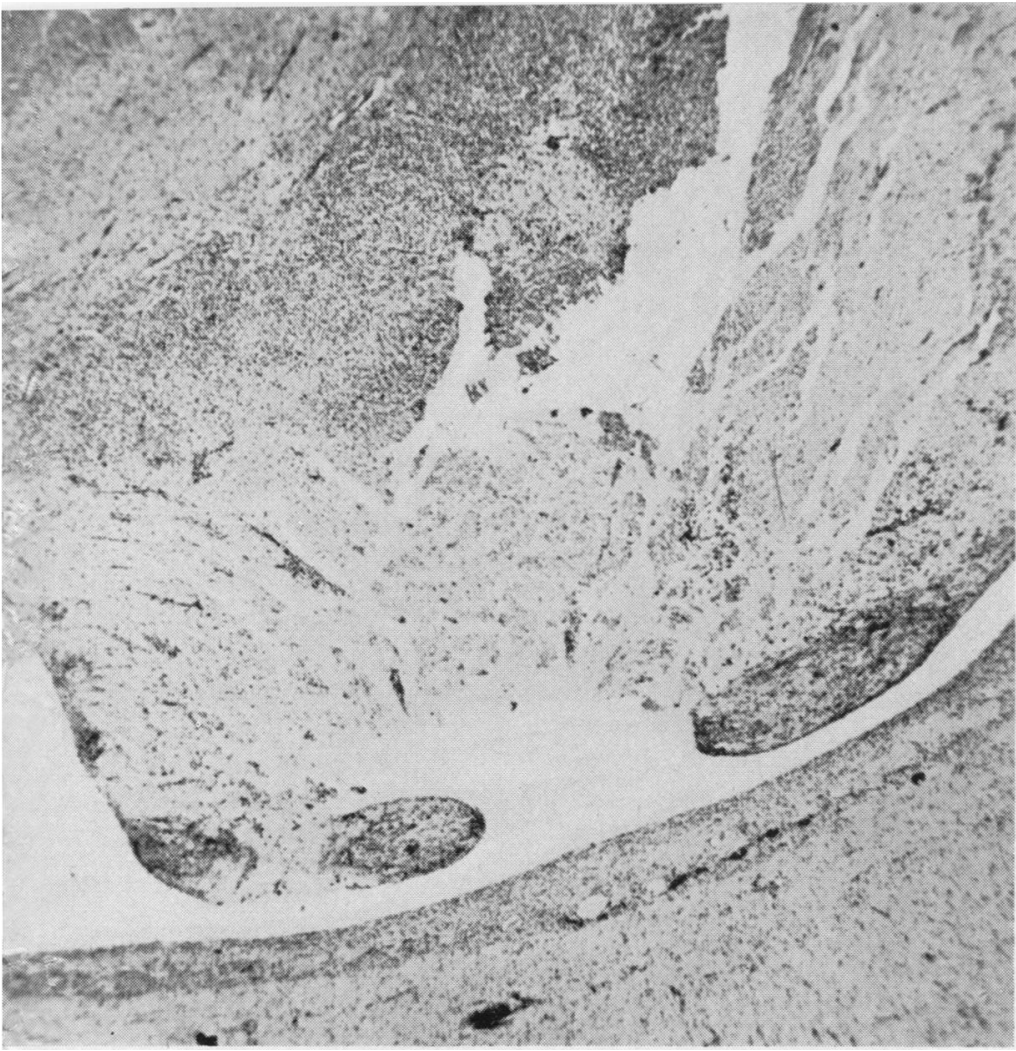

FIG. 6.-An area of softening breaking into the ventricle. Cresyl violet $\times 30$. discoloration, was present on the medial surface above the corpus callosum. The lateral and third ventricles were dilated. The bestformed part was, as in the right hemisphere, the temporal lobe. No calcification could be detected on naked-eye examination.

The main features elicited by the histological examination were cytoarchitectonic details of the microgyria and the presence of focal cerebral necrosis.

The microgyric cortex was formed in most areas by a fairly uniform molecular layer and a deeper cellular layer of round neurones with no evidence of further lamination (Fig. 4). Most of the sulci were shallow, some being scarcely indicated on the surface, and the neuronal layer between and beneath them was convoluted accordingly, presenting either gentle or more acute temporal gyrus close to its junction with the fusiform, and the surface of the brain around it had a brownish tinge. With the exception of the temporal lobe, gyri on the external aspect of the hemisphere bore no recognizable relation to the normal pattern. The medial aspect of the hemisphere was better developed (Fig. 3). The cingulate gyrus was relatively well formed, and the calcarine and parieto-occipital sulci were identifiable and in normal position. Microgyria were, however, superimposed upon the basic gyri. The corpus callosum was minute, $1.2 \mathrm{~cm}$. in length and only a fraction of a millimetre in thickness. The fornix was very thin, but the foramen of Monro was identifiable. Only the optic, third and fifth cranial nerves, all very small, were recognizable. The brain-stem and the cerebellum were relatively large and normal. The spinal cord was thin but otherwise normal.

When the left hemisphere was partially reconstituted from the remaining blocks preserved in formalin, it proved generally similar to the right in size and shape, but there was no porencephaly on the lateral surface. A large deficiency $(5.3 \times 0.8 \mathrm{~cm}$.), covered by a layer of meninges, and bordered by areas of rusty-red

FIG. 7.-Mening i-cortical plaque. Haematoxylin and eosin

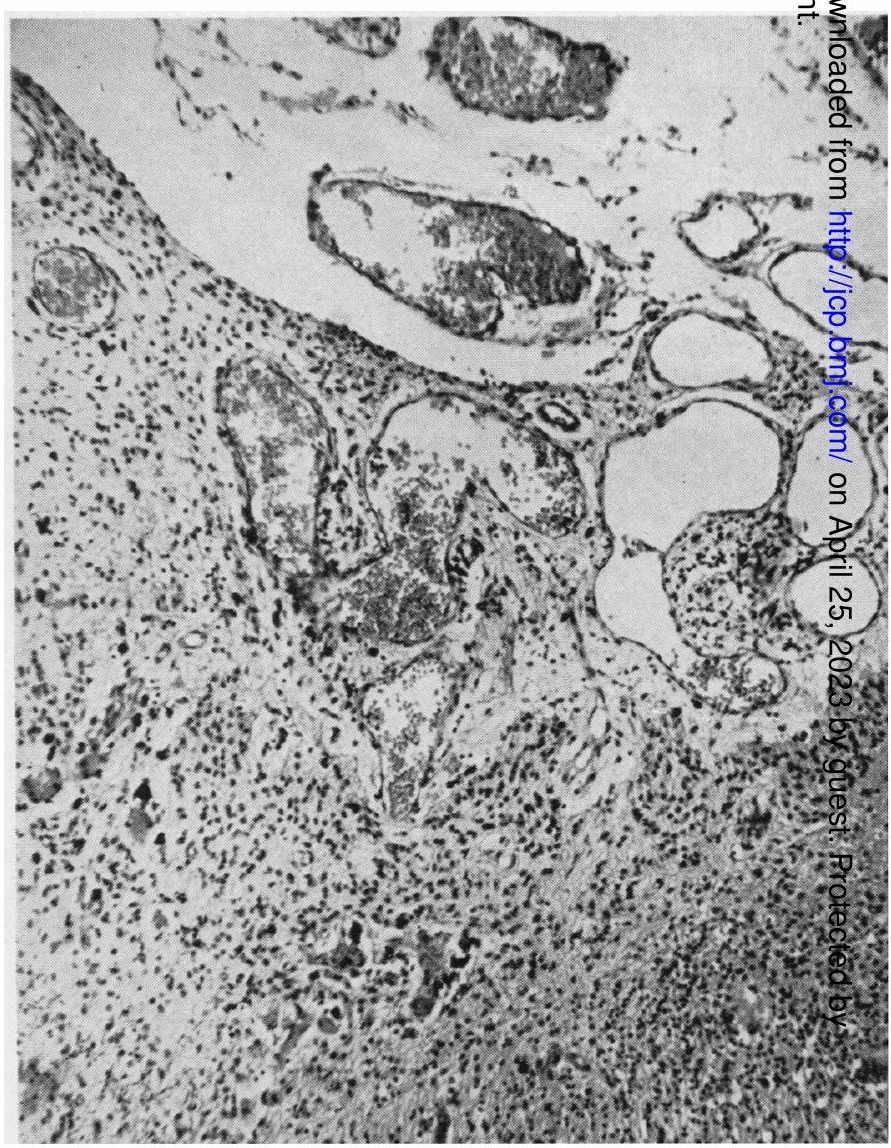


undulations, and bearing in places rounded or square extensions directed towards the surface of the brain. Where gyri were uncommonly numerous, they were sometimes cut tangentially and parts of a second neuronal layer would then appear deep to the external one. The above basic pattern was often modified. Focal deficiencies of neurons were present in the neuronal layer. A few rarer areas showed also a more "classical" type of microgyric lamination consisting of four layers: (1) molecular, (2) densely cellular neuronal, (3) sparsely cellular, and (4) deep neuronal merging with the subjoining "white matter." Some axon cylinders were present in the molecular and third layers, which contained, however, no trace of myelin sheaths. Lastly, the more mature cortical areas in the temporal and, to a lesser extent, occipital. lobes had broader and thicker gyri with deeper sulci, and showed also some indication of normal stratification and neuronal differentiation.

The centrum semiovale was formed by a dense reticulum of fine fibres and a moderate number of glial cells. Many of these cells could not be classified with any certainty; some were unipolar spongioblasts, others more mature astrocytes and oligodendrocytes. Axon cylinders were numerous but there was no evidence of myelination. Many dense round and columnar foci of undifferentiated matrix cells were situated in the "white matter" (Fig. 5), chiefly around, and some distance from, the ventricles.

The ventricles were lined by tall columnar ciliated epithelium, but this was largely denuded. Some ependymal granulations were also present, and in a few areas the ependyma had grown inward into the periventricular tissue, either diffusely or in the form of single or multiple tubules. Haemosiderin was present upon the surface of the choroid plexus.

The necrotic areas varied in size and structure. Some were situated in the cortex, others periventricularly, while at least two had traversed the entire thickness of the hemisphere forming a narrow, irregular, cleft-like communication between the surface and the ventricles. The seemingly fresh lesions showed rarefaction or complete softening and contained many fat-laden phagocytes with some anisotropic intra- and extracellular debris, particles of calcium, and haemosiderin granules. Where the softened tissue had broken into the ventricles, the gap was encircled by a collar of thickened ependymal tissue (Fig. 6). Other, presumably older, foci of necrosis showed less phagocytosis and cellular proliferation and more calcification. These foci were mainly periventricular, the largest being situated in the centre of the superior medullary velum and measuring some $3 \mathrm{~mm}$. in diameter. In addition to the necrosis, there were also many small fresh haemorrhages in the meninges and brain, and some of the intracerebral blood vessels were cuffed by phagocytic fat-containing cells.

The meninges were normal over most of the cortex, but above and around areas of cortical necrosis they were thickened and fused with the subjoining tissue forming flat or wedge-shaped plaques (Fig. 7). These consisted of meningeal and glial cells with an increased amount of collagen and reticulin. Blood vessels in these plaques were dilated and often plexiform. Many macrophages containing neural fat with calcium and haemosiderin granules were present in the interstices of the tissue.

Where examined, the basal ganglia seemed better developed and preserved than the cortex, but no detailed anatomical study was attempted. The cerebellum was normal, although the ependyma over the fourth ventricle showed some "granulations." The brain-stem and spinal cord also seemed normal for the stage of development showing some myelination of fibre tracts.

Cytomegalic inclusions were searched for in many sections stained by the usual methods, including Lendrum's phloxine tartrazine. No certain inclusions were found, but a few cells among the phagocytes in the necrotic areas were, perhaps, equivocal. Their cytoplasm contained irregular or rounded, more or less eosinophilic bodies, surrounded by a clear halo. These could be interpreted as modified inclusions, but it seemed more reasonable to regard them as ingested particles. Intranuclear inclusions were certainly absent in the many sections examined.

\section{Discussion}

The clinical features of the present caseneonatal jaundice, ascites, hepatomegaly, splenomegaly, anaemia, erythroblastaemia, and widespread haemorrhages-were those usually found in neonatal generalized cytomegalic inclusion disease (France, 1951), and also resembled closely the picture in the previously described cases with microgyria. The pathological features in the central nervous system showed certain differences. Inclusions were not found in the present case and calcification was not as gross as in the previous instances. Porencephaly was absent in the earlier cases, which showed, however, like the present one, 
focal necrotic change. The temporal and the occipital lobes were better developed in both the present and in Diezel's case than the other parts of the cortex, and microcephaly was also a common feature. Despite the differences, the clinical and morphological similarity seems remarkable and strongly suggests that the cases are instances of the same disease.

Viewed as microgyria, the present case is somewhat anomalous. The abnormal pallium in older individuals with this condition is usually characterized by easily recognizable and widespread four-layer lamination. The marginal layer contains few nerve cells. The second layer is densely cellular, while the third is sparsely cellular, containing many myelinated nerve fibres which extend at intervals as stout radial bundles into the core of the overlying microgyric convolutions. The deepest, fourth layer contains again nerve cells. This arrangement was modified in the present case. The typical four-layer lamination was rare, while the first and third layers contained no myelin. These differences are probably accounted for by the immaturity of the present brain. No myelin was in fact present in any part of the centrum semiovale, and the numerous islands of undifferentiated matrix cells indicated incomplete migration of neuroblasts to the periphery. It is likely that, had the child lived, continued maturation would have resulted in a more typical picture.

While the occasional association of cytomegalic inclusion disease with microgyria is thus established, it is impossible to accept unreservedly Diezel's contention that the former is a virus infection and that the association of the two is sufficient evidence of the infective origin of microgyria in such cases.

Current views on the nature of cytomegalic inclusion disease may be summarized as follows. Although the inclusions of cytomegalic inclusion disease have been reported in the salivary glands of $10 \%$ to $30 \%$ of infants examined by routine necropsy, the generalized disease is far less common, somewhat more than 100 necropsy cases having so far appeared in the literature. Only two fatal cases occurred in the neonatal period at the Mothers' Hospital during 1948 to 1959 of a total of 20,220 infants delivered.

There is strong evidence in favour of human cytomegalic inclusion disease being due to a species-specific salivary gland virus comparable to that isolated from mice (Smith, 1954). Later, Smith (1956) recovered viruses from two human cases producing cytopathological change in cultures of human fibroblasts like those which are pathognomonic of cytomegalic inclusion disease. These results were obtained from the salivary gland of an infant showing typical inclusion cells histologically, and from the kidney of an infant dying with the generalized disease. Both viruses were neutralized by the serum of infants dying of cytomegalic inclusion disease and by the mother of an affected infant. Similar viruses have been isolated from spontaneously degenerating tissue cultures of human adenoids (Rowe, Hartley, Waterman, Turner, and Huebner, 1956), and from infants with illnesses resembling cytomegalic inclusion disease (Weller, Macauley, Craig, and Wirth, 1957).

Even if cytomegalic inclusion disease is a virus disease, its occasional association with microgyria may be fortuitous: a foetus with a neural malformation may be infected later. It is therefore important to continue reporting such cases: the causal relationship between the two would be strengthened by larger numbers, especially if they remain as similar to each other, clinically and pathologically, as they have been hitherto.

Whatever the trend of future observations, it is certain that cases of microgyria without any evidence of cytomegalic inclusion are common. Thus, of 282 brains of individuals with encephalopathy or mental retardation examined at the Fountain Hospital, 16, including the present one, showed microgyria. Four of the 16 showed no cytomegalic inclusions in the brain or elsewhere ; examination of the others is still incomplete. Hence cytomegalic inclusion disease could be only one of several causes of microgyria, and this is not surprising, since it is well known from experimental work that the same malformation may be produced in different ways. Thus, a condition closely resembling human microgyria and pachygyria, another cerebral malformation having many features in common with microgyria (Crome, 1956), was, for example, successfully reproduced in rats (Riggs, McGrath, and Schwarz, 1956) by exposing pregnant animals to irradiation five to nine days before confinement. Human pachygyria after maternal irradiation by $x$ rays during pregnancy had been previously reported by Uiberrak (1942), and a case of microgyria in a child born to a mother after an attempted suicide with carbon monoxide in the fifth month of the pregnancy by Hallervorden (1949).

\section{Summary}

Several instances of microgyria associated with cytomegalic inclusion disease have been observed 
by previous authors. A further example is presented in this communication and the significance of the association discussed.

Our thanks are due to Dr. H. M. M. Mackay for permission to publish the clinical details of this case.

\section{REFERENCES}

Crome, L. (1952). J. Path. Bact., 64, 479. (1956). Ibid., 71, 335.

Diezel, P. B. (1954). Virchows Arch. path. Anat., 325, 109.

France, N. E. (1951). Arch. Dis. Childh., 26, 588.

Hallervorden, J. (1949). Allg. Z. Psychiat., 124, 289.

Hartmann, G. (1948). Klin. Med. (Wien), 3, 281 and 344.

Haymaker, W., Girdany, B. R., Stephens, J., Lillie, R. D., and Fetterman, G. H. (1954). J. Neuropath., 13, 562.
Mercer, R. D., Luse, S., and Guyton, D. H. (1953). Pediatrics, 11 502.

Morris, D. (1953). Lancet, 1, 1284

Nellhaus, G. (1958). New Engl. J. Med., 258, 935.

Reilly, W. A., Hinman, F., Pickering, D. E., and Crane. J. T. (1958). Amer. J. Dis. Child., 95, 9.

Riggs, H. E., McGrath, J. J., and Schwarz, H. P. (1956). J. Neuropath., 15, 432.

Rowe, W. P., Hartley, J. W., Waterman, S., Turner, H. C., and Huebner, R. J. (1956). Proc. Soc. exp. Biol. (N.Y.), 92, 418.

Smith, M. G. (1954). Ibid., 86, 435. (1956). Ibid., 92, 424.

Thiersch, J. B. (1956). Proceedings of 5th International Conference on Planned Parenthood, Tokyo.

Uiberrak, Frau (1942). Z Zbl. allg. Path. path. Anat., 80, 187.

Weller, T. H., Macauley, J. C., Craig, J. M., and Wirth, P. (1957). Proc. Soc. exp. Biol. (N.Y.), 94, 4.

Wilkins, L., and Jones, H. W. (1958). Pediatrics, 21, 513. 